\section{Soviet Union puts a Frenchman and two Russians into space}

Paris

ON Saturday evening (26 November), a Soviet Soyouz-TM launcher sent a Frenchman, Jean-Loup Chrétien, and two Soviet cosmonauts, Alexandre Volkov and Serguei Krikalev, on a two-day voyage to the Mir space station, where they will stay for three weeks. For Soviet cosmonauts, this kind of mission has become almost routine - three have spent more than 320 days aboard Mir - but it will provide European space scientists with their first chance to collect physiological data over a prolonged period in preparation for the European Space Agency's own projected manned flights aboard the Hermes shuttle at the end of the century.

Chrétien, aged 50, is Europe's most travelled astronaut. In 1982, he took part in another Soviet mission to the Salyut-7 space station. On the present mission, Aragatz, he will join one of his Soviet

\section{New ESA project}

\section{Paris}

The European Space Agency (ESA) has chosen the Cassini/Titan probe mission as its next space science project, six years after it was first proposed. Four other missions were in competition for a vacant slot in ESA's Horizon 2000 long-term space science plan (see Nature 336, 98; 10 November 1988). The final decision was made at the science programme committee's meeting on 24 November in Paris

Cassini is a joint mission, in collaboration with the US National Aeronautics and Space Administration (NASA), to explore the atmosphere of Saturn's moon. Titan. Titan is the largest moon in the Solar System, and its nitrogen-rich atmosphere could contain a variety of pre-biotic molecules, providing a possible model for the origins of life on Earth.

NASA will provide the Saturn orbiter which will circle the planet for four years. passing over Titan more than 30 times and coming to within $1,000 \mathrm{~km}$ of its surface. ESA's Titan probe, named Huyghens, will be released into the moon's atmosphere as soon as the orbiter reaches Saturn, slowing to an impact velocity of 5 metres per second, while the orbiter relays data from the probe to Earth.

Although ESA scientists have contributed individually to other planetary exploration missions, the Giotto mission to comet Halley is the only ESA project to have explored a body in the Solar System other than Earth. The choice of Cassini, due for launch by NASA in April 1996. marks ESA's intention to become directly involved with planetary exploration.

Peter Coles

\section{London}

IN an attempt to prove to the electorate that its conversion to environmentalism is real, the British government is to hold a world conference in March next year on the protection of ozone in the stratosphere. Announcing the conference last week, $\mathrm{Mr}$ Nicholas Ridley (right), Secretary of State for the ready for operation in 1991 . antenna and experimental instruments designed to collect data on the different kinds of stress to which external structures are subjected in space. But the principal interest for European scientists lies in two biomedical studies on man's physiological response to prolonged weightlessness, code-named PHYSALIE and VIMINAL.

These two studies have been designed by Alain Berthoz, a neurophysiologist at the Centre National de la Recherche Scientifique (CNRS) laboratory for neurosensory physiology, in collaboration with the Moscow Academy of Science, to investigate perceptual-motor adaptation to microgravity conditions. PHYSALIE will collect data on postural adaptation and changes in muscle response; VIMINAL will look at visual-manual manipulation of objects and orientation.

On the eve of the flight. Hubert Curien. the French research minister, who was president of the national centre for space research (CNES) in 1980, lent his support to France's controversial backing of manned space missions, in an article in the national daily newspaper, Le Monde. The value of manned missions was contested in a report by the French Academy of Sciences (see Nature 333, 2; 12 May 1988), on the grounds that astronauts can perform no useful functions that could not better be carried out by robots. But for Curien, not to participate now in manned missions would make Europe a "secondrate continent" dependent upon the "regal gift of know-how gained by our two major partners [the Soviet Union and the United States] without us".

Peter Coles colleagues in a 'space walk' to assemble an

\section{UK public says 'no, thanks' to nuclear waste}

\section{London}

As the search continues in Britain for a deposit for the nuclear industry's lowand intermediate-level nuclear waste. the public have overwhelmingly rejected one of the options being considered: a repository under the sea-bed which is accessible from a structure like an oil-rig, based offshore. The option gained little support because of concern over radioactive contamination of the sea. The attitude of the public to the plans of United Kingdom Nirex Limited, the industry's waste disposal body, was assessed by the University of East Anglia's environmental assessment unit, in response to a document circulated by Nirex last year for public discussion. Though the sub-sea-bed option was not popular with the public. Nirex does not rule it out.

Nirex proposed three deep disposal options: an underground depository inland; a depository under the sea-bed, with access from land, and a depository under the sea-bed, with access from an off-shore structure. In response, a large number of people did not specify a choice, rejecting outright any site in their area. And there was strong support for on-site storage of waste, except from people in areas with existing nuclear installations; there were some responses in favour of deep disposal from the public near the nuclear stations at Dounreay in Caithness. Scotland. and at Sellafield in Cumbria. It is likely that if Nirex does select a site - and it aims to do so by February next year - then it will be one of these.

Christine McGourty

\section{British government promotes atmosphere of concern}
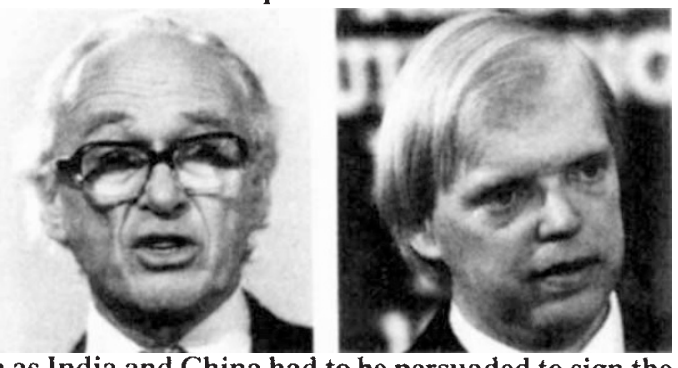

Environment, said that countries such as India and China had to be persuaded to sign the Montreal Protocol. Their lack of action to protect the ozone layer was due to a lack of information about ozone-benign products and technologies, he said; the aim of the conference will be to provide such information. In April 1990, Britain will host the second meeting to review the Montreal Protocol; the first will be held in Finland in April next year. Lord Caithness (far right), the environment minister, is currently trying to persuade other European Community ministers to ratify the protocol.

At the same time, the race to produce replacements for the chemicals that destroy stratospheric ozone stepped up with the announcement by Britain's biggest chemical company, Imperial Chemical Industries, of the construction of two $£ 30$ million commercial plants to produce HFC-134a - a hydrocarbon not containing chlorine. They will be
Christine McGourty 